\title{
Influence of Weather on the Eurasian Woodcock's Breeding Display
}

\author{
CHRISTOPHER J. HEWARD, ${ }^{1}$ Game \& Wildlife Conservation Trust, Burgate Manor, Fordingbridge, SP6 1 EF. UK
}

ANDREW LOWE, Birklands Ringing Group, 159 Sherwood Street, Market Warsop, Mansfield, NG20 oJX. UK

GREG J. CONWAY, British Trust for Ornithology, The Nunnery, Thetford, Norfolk, IP24 2PU. UK

ANDREW N. HOODLESS, Game \& Wildlife Conservation Trust, Burgate Manor, Fordingbridge, SP6 1EF. UK

\begin{abstract}
Counts of displaying male Eurasian woodcock (Scolopax rusticola) form the basis for breeding Eurasian woodcock surveys in many regions across Europe and provide the only practical method of assessing the species' abundance. This paper investigates the effect that weather may have on the results of these surveys, principally considering its influence upon Eurasian woodcock display behavior and detectability by surveyors. We assessed data from an annual Eurasian woodcock survey conducted in the Britain during 2004-2015 and correlated them with a number of weather variables. This is supplemented by tracking data gathered from 19 male Eurasian woodcock to assess how weather might affect each individual's decision to display. We found that counts of roding Eurasian woodcock were positively related to the amount of rainfall in the 2 weeks preceding the survey and negatively related to wind speed on the evenings that surveys were conducted. The likelihood that tagged male Eurasian woodcock displayed decreased in relation to wind speed and increased in relation to minimum air temperature. To guarantee that counts of displaying males provide a representative measure of abundance, we recommend that surveys consist of at $\geq 3$ visits to each site within each year, that visits are spread as widely as possible across the peak displaying season, and that analyses are based on maximal counts rather than means to reduce the effects of surveys conducted in sub-optimal weather conditions.
\end{abstract}

Proceedings of the American Woodcock Symposium 11: 209-216

KEY WORDS: abundance, census, Eurasian woodcock, national survey, rainfall, remote-sensing, Scolopax rusticola, temperature, UK

The breeding display flight of the Eurasian woodcock (Scolopax rusticola) offers a unique opportunity to survey a species that is otherwise rarely observed. Eurasian woodcocks' cryptic plumage and behavior means that encounter rates during the breeding season are generally low and that traditional diurnal bird surveys, such as those used for other woodland birds (e.g., Hewson et al. 2007, Hewson and Noble 2009), are unrepresentative. The display flight, known as 'roding', contains conspicuous visual and vocal signals that provide an effective means of assessing site occupancy and the relative abundance of Eurasian woodcock.
Display flights are performed over roding grounds ranging in size from 43 to 134 ha (Hirons 1980) and are accompanied by a continuous repeated 2-part call (Hoodless et al. 2008). The roding grounds of several males may overlap (Hirons 1980) and the behavior appears to be a signal for female mate selection rather than male-male territoriality (Hirons 1980). Males perform their displays at dawn and dusk between February and July, with roding behavior peaking during May and June (Hoodless et al. 2006).

Counts of roding Eurasian woodcock form the basis of breeding Eurasian woodcock surveys in several European regions, including Switzerland, France, the Azores, and

1 email: cheward@gwct.org.uk 
western Russia (Estoppey 2001, Ferrand et al. 2008, Machado et al. 2008, Fokin and Blokhin 2013), where measures of Eurasian woodcock activity or 'roding intensity' are used as an indicator of Eurasian woodcock abundance. The Eurasian woodcock is a quarry species in most European countries (Lutz 2005), and these surveys can be used to guide more sustainable hunting practices, particularly where migrant and resident Eurasian woodcock populations overlap.

A national survey of Eurasian woodcock in Britain, for instance, uses a calibration equation to convert surveys of roding activity into estimates of population size (Hoodless et al. 2009), and found a $29 \%$ decline in the British breeding population between 2003 and 2013 (Heward et al. 2015). Roding surveys are the only effective way of detecting breeding population trends as alternative methods conducted in winter, such as hunting bag analyses (e.g. Seamans and Rau 2017), are confounded by the large numbers of migrant Eurasian woodcock that winter alongside British breeders (Hoodless et al. 2013). In Britain, voluntary guidelines for hunters were produced in an attempt to minimize the impact of hunting on the declining resident component of the wintering population (Game \& Wildlife Conservation Trust 2017). Continued monitoring of the resident population will help gauge the effectiveness of these measures and, if necessary, could form the grounds for tighter control in the future.

The British breeding Eurasian woodcock survey was conducted at approximately 800 randomly selected sites in 2003 and 2013 (Heward et al. 2015). A non-random sub-sample of these sites, surveyed on an annual basis in the intervening years, demonstrated a yearly decline of $4.9 \%$ (Heward et al. 2015). However, these annual surveys were also characterized by a high degree of annual variation, and weather was suggested as a possible cause for these fluctuations. There is already evidence that roding activity can be influenced by weather conditions during the roding period, although Hoodless et al. (2006) suggest that these must be relatively severe before they have a significant effect. If more subtle variations in weather influence the roding behavior of Eurasian woodcock, these need to be considered in the design and interpretation of roding Eurasian woodcock surveys. Moon phase may also influence the behavior of crepuscular species, although this has been demonstrated more clearly for mammals (Prugh and Golden 2014) than for birds (Mills 1986). We propose 4 ways in which weather might influence the results of roding Eurasian woodcock surveys: 1 ) if weather has a direct impact on survival or productivity in the previous breeding season, 2) if the prevailing weather prior to a survey affects individual fitness and therefore the likelihood of display behavior, 3) if weather during the survey period affects the likelihood of display behavior, or 4) if weather during the survey period affects detectability by the surveyor.
We investigate the relationship between roding survey results and weather, using Eurasian woodcock survey data collected over a 12-year period. The influence that weather has on the display behavior of male Eurasian woodcock is assessed using the tracking data gathered from a sample of 19 male Eurasian woodcock tagged with archival GPS loggers.

\section{Methods}

\section{REPEAT RODING EURASIAN WOODCOCK SURVEYS}

Roding Eurasian woodcock surveys were conducted at woodland sites across Britain between 2004 and 2015 . These followed a large-scale national Eurasian woodcock survey conducted in 2003 in which counts of roding males were made at 807 randomly- elected 1 x 1-km squares across England, Scotland, and Wales (Hoodless et al. 2009). Observers taking part in the 2003 survey were encouraged to continue their counts on a yearly basis, resulting in a sub-sample of sites, all of which were occupied by Eurasian woodcock, receiving repeated visits in subsequent years. These were supplemented by 2 additional sites conducted in non-random squares. Ideally, these repeat surveys would have been conducted at an entirely random selection of sites, but this was not possible without increasing the risk of reduced uptake or poor continuity of surveys.

Each survey site was visited up to 3 times per year between the start of May and the end of June, with each visit $\geq 1$ week apart. Volunteers selected a suitable count point where roding could be observed, generally a woodland clearing or the intersection of 2 open trails where the absence of canopy cover allowed a clear view of the sky (British Trust for Ornithology 2013). The same count point was used in successive years unless the development of surrounding vegetation meant that the point had to be moved to a new, more suitable location nearby. Volunteers recorded each separate occasion that a Eurasian woodcock was seen or heard as a single 'registration'.

Volunteers recorded 3 weather variables for each visit. Cloud cover was assigned to 1 of 3 broad categories: 0 $33 \%,>33-66 \%,>66-100 \%$. Wind strength was rated as calm, light, or moderate (equivalent to o, 2 , and 4 , respectively on the Beaufort Scale). Rainfall was categorized as 'no rain', 'drizzle' (very light, continuous rain) or 'showers' (moderate, intermittent rain). Surveys were not conducted if rain was persistent, or if the wind exceeded Beaufort Scale 4.

We obtained daily rainfall data from the Centre for Ecology and Hydrology's (CEH) CEH-GEAR dataset (Tanguy et al. 2016) and, for each survey, we calculated the total rainfall on the day of the survey ('survey day' $d=0$ ), total rainfall for the week preceding the day of the survey ('survey week' $=d-7$ to $d-1$ ), and for the week before this ('previous week' $=d-14$ to $d-8$ ). For the same periods, we 
extracted mean and minimum temperature from the Met Office's UKCPog dataset (Met Office 2017a). Both datasets are interpolated raster maps based on observations from national Met Office weather stations.

We sourced moon phase data from a moon phase generator available online (somacon.com 2011). This gives the date of each full moon and new moon within the study period. We then used these dates to assign surveys to 1 of 3 categories: if conducted on the night of a new moon or full moon, or within 3 days either side, they were classified as 'new' or 'full', respectively, otherwise, they were classified as 'transitional.'

We placed survey sites into 1 of 4 geographic regions based on their location: Scotland, Northern England, East Anglia and the Midlands, and South-east England. These regions derive from natural groupings in the distribution of repeat survey sites and follow logical geographic divisions (Fig. 1). We extracted the total area of woodland within a $1-\mathrm{km}$ radius buffer of the count point from the CEH's Land Cover 2007 dataset (Morton et al. 2011). Woodland area is known to have a strong effect on the number of Eurasian woodcock registrations recorded at a site (Heward et al. 2015), hence its inclusion in the analyses described below.

We analyzed data using a generalized linear mixed model (GLMM) with a Poisson distribution and a logarithmic link function. The analysis was conducted in $\mathrm{R}(\mathrm{R}$ Development Core Team 2016) using the glmmPQL function within the Mass package (Venables and Ripley 2002). We specified the number of Eurasian woodcock registrations recorded on each survey as the dependent variable. The fixed effects were mean temperature on the survey day, during the survey week, and previous week; total rainfall on the survey day, during the survey week, and previous week; moon phase; cloud cover and wind during the survey as recorded by the surveyor; day of year; and wooded area. We specified site, nested within region then year (with year as a categorical variable), as a random effect. We did not include rain during the survey, as recorded by surveyors, as a factor given a very heavy bias towards surveys experiencing no rain at all $(n=838 / 886)$. We also re-ran this model substituting minimum temperature for the mean temperature and the natural log of the minimum temperature.

\section{TRACKING MALE EURASIAN}

\section{WOODCOCK WITH GPS LOGGERS}

We captured Eurasian woodcock in mist-nets in 2 large woods (each ca. $10-14 \mathrm{~km}^{2}$ ), in Nottinghamshire, UK (Lat: 53.186 N Long: 1.093 W) during the breeding seasons of 2015-2016 (Heward et al. 2017). We tagged 19 male Eurasian (2015: $n=5,2016: n=15$ (1 individual was tagged in both years)) with a 7.5-g tag combining an archival GPS logger (Lotek PinPoint 50, Newmarket, Ontario, Canada)

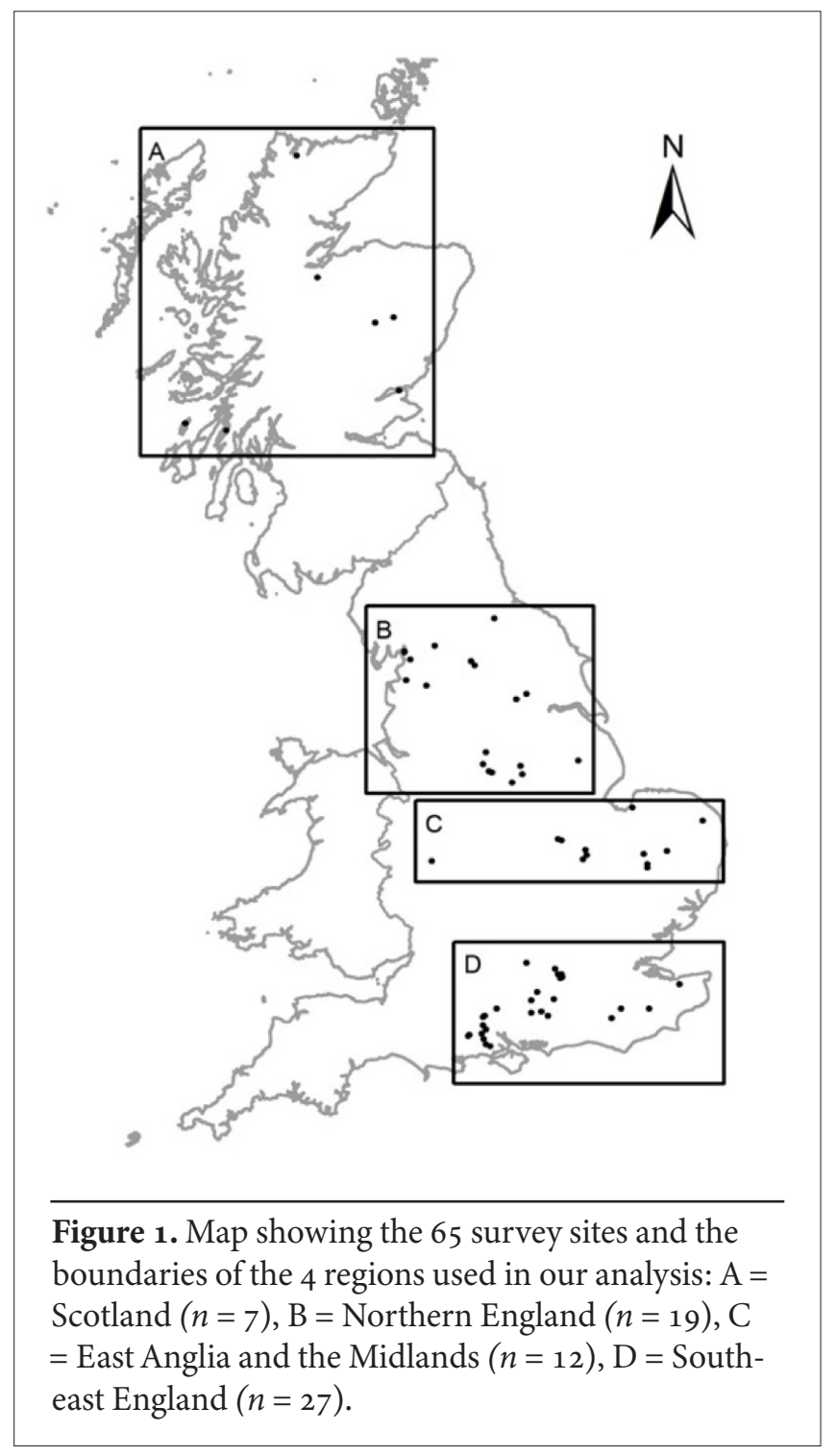

and a VHF radio (Perdix Wildlife Supplies, Stratford-Upon-Avon, UK). For most captured Eurasian woodcock $(68 \%)$, roding behavior immediately prior to capture indicated that the individual was a male. When we could not determine sex based on behavior, we identified males based on the appearance of the cloaca [as described for other Charadriiformes (Tomkovich and Soloviev 1996, Giunchi and Pollonara 2007)], lack of a brood patch, or using biometric data (Ferrand and Gossmann 2009). We aged captured individuals as juvenile (first-breeding season) or adult ( $\geq 2$ breeding seasons) based upon their wing molt (Ferrand and Gossmann 2009). We attached tags to the skin of the synsacrum and a small number of surrounding feathers using a gauze mount and cyanoacrylate glue. Tagging was conducted under a license issued by the British Trust for Ornithology.

GPS loggers began recording 5 days after tagging, allowing individuals to acclimatize to the tag. Locations 
were recorded at 1-minute intervals during the typical dusk display period; beginning 15 minutes before sunset and continuing for 90 minutes. This schedule was repeated every subsequent evening for 1 to 6 days depending upon the rate of battery depletion. We recovered tags by recapturing the individual or by using the VHF radio signal to relocate tags once shed.

We obtained weather data from the UK Met Office's observation station at Watnall, UK (Lat: $53.005 \mathrm{~N}$ Long: $1.250 \mathrm{~W}$; Met Office $2017 \mathrm{~b}$ ), approximately $20 \mathrm{~km}$ from the tracking locations. We extracted daily rainfall, daily minimum temperature, and daily mean wind speed for each evening on which tracking data were recorded.

We classified each Eurasian woodcock, for each evening it was tracked, as 'roding' or 'non-roding' based upon its tracking data; for most individuals the distinction between the 2 types of behavior was obvious. Tracking data from roding individuals showed a period of almost constant movement for $\geq 30$ minutes during the core of the roding period. For non-roding individuals, movements were short in duration and direct, typically consisting of a single flight between a roost site and a presumed feeding area (Fig. 2).

We assessed the correlates of 'roding' and 'non-roding' behavior using a binomial GLMM with a logit link function in R's MASS package. The independent variables tested were total rainfall, minimum temperature, and mean wind speed on the day that tracking data were recorded, and the individual's age. We specified 'individual' as a random effect to account for differences among tagged individuals. As a

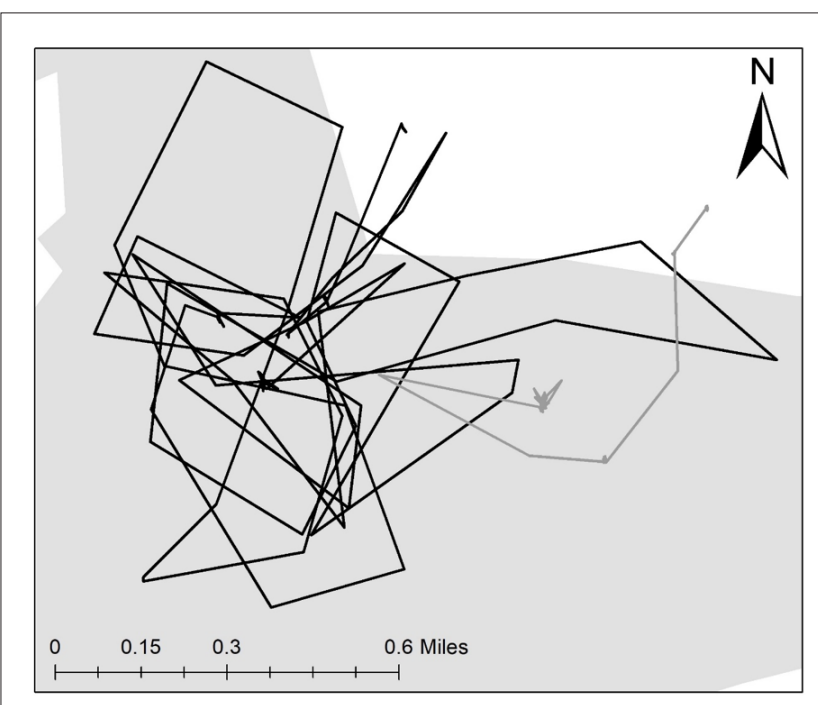

Figure 2. Map showing typical 'roding' (black) and 'non-roding' (gray) location data from 2 Eurasian Eurasian woodcock tagged with GPS loggers. Each example shows 190 -minute tracking period. The gray shaded area shows the extent of woodland. comparison, we created a 'null' model in which age and day of year were the only explanatory variables.

\section{Results}

\section{RODING EURASIAN WOODCOCK SURVEY SITES}

In total, 65 survey sites received repeated visits (Fig. 1). Few sites were visited every year between 2004 and 2015, but on average each site was surveyed 5.0 different years during the 12 -year period. We excluded from analysis sites that were visited in fewer than 3 of the 12 years. The average number of sites visited per year was 26.6. Because of their self-selected nature, the average number of contacts with Eurasian woodcock recorded at these 65 sites [mean registrations $=9.57 \pm 0.26(1 \mathrm{SE})]$ was higher than the national average [mean registrations $=7.45 \pm 1.03(1 \mathrm{SE})$ at occupied sites] recorded in the large-scale national survey of 2003.

\section{RODING SURVEYS AND WEATHER}

The multivariate analysis of Eurasian woodcock survey data revealed significant relationships with 3 weather variables: 2 measures of rainfall and the wind speed variable. There was a positive relationship with rainfall during both the survey week (glmmPQL: $\mathrm{t}_{550}=2.81, P=0.005,0.051 \pm$ 0.018 ) and the previous week (glmmPQL: $\mathrm{t}_{550}=2.70, P=$

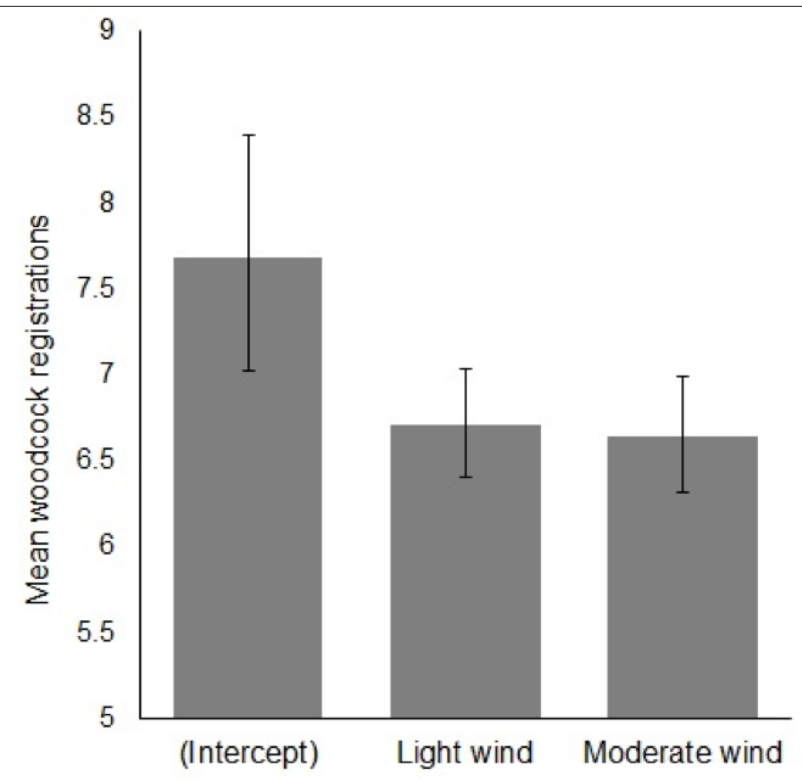

Figure 3. The mean number of Eurasian woodcock registrations recorded on roding surveys, in relation to three categorical wind variables: still, light wind (approximately 1-2 on the Beaufort Scale), and moderate wind (approximately 3-4 on the Beaufort Scale). Values are back-transformed from our roding survey GLMM to account for the effects of other explanatory variables. Error bars show 1 SE. 
$0.007,0.046 \pm 0.017$ ) but no relationship with total rainfall on the survey day.

Wind during the 75-minute survey period was correlated with the number of Eurasian woodcock registrations (Fig. 3), with the number of registrations being lower when wind was classified as 'light' (glmmPQL: $t_{550}=-2.95$, $P=0.003,-0.136 \pm 0.046)$ or 'moderate' (glmmPQL: $t_{550}=$ -2.98, $P=0.003,0.151 \pm 0.051)$ compared to 'still'.

No significant relationships were found between the number of Eurasian woodcock registrations recorded and the minimum temperature variables. When the model was re-run using the natural logs of minimum temperature, however, the temperature during the survey week was associated with the number of Eurasian woodcock registrations (glmmPQL: $t_{550}=2.19, P=0.029,0.055 \pm 0.024$ ). In the model using mean, rather than minimum, temperatures we found no significant relationships with temperature, and relationships with other weather variables remained consistent with those in the model that included minimum temperature.

Moon phase, day of year, and total wooded area were not related to the number of Eurasian woodcock registrations, nor was cloud during the survey, but for the latter, $\mathrm{P}$-values were close to statistical significance when comparing between cloud cover of $66-100 \%$ and $0-33 \%$ (glmmPQL: $\left.\mathrm{t}_{550}=-1.90, P=0.058,-0.083 \pm 0.046\right)$.

\section{TAGGED EURASIAN WOODCOCK AND WEATHER}

The probability of Eurasian woodcock roding was related to minimum temperature and mean wind speed. As the daily minimum temperature increased, so did the likelihood of display behavior being observed (glmmPQL: $\mathrm{t}_{32}=3.51, P=$ $0.001,3.574 \pm 1.016$; Fig. 4a). For tagged individuals, roding became less likely as wind speed increased (glmmPQL: $\mathrm{t}_{32}$ $=-2.25, P=0.031,-1.711 \pm 0.757$; Fig. $4 \mathrm{~b}$ ). There was no significant effect of rainfall or Eurasian woodcock age. In the 'null' model, containing only age and day of year, neither variable was significantly related to probability or roding.

\section{Discussion}

\section{RAINFALI}

The number of Eurasian woodcock registrations recorded during roding surveys was positively related to rainfall, but only when rainfall was measured over a week or more prior to the survey. Lower rainfall in spring or summer is likely to drive the soil-dwelling invertebrates on which Eurasian woodcock feed deeper into the soil (Gerard 1967, Hoodless and Hirons 2007), and poorer foraging conditions may leave Eurasian woodcock with less energy to expend on display during dry spells. Dry summers have been demonstrated to have a negative effect on reproductive success in Eurasian woodcock populations (Guzmán and Arroyo 2015), but the potential effect on adult body condition remains unclear.
Had there been a significant relationship with rainfall during the survey, a negative association might be expected, assuming that heavy rain reduces the male's ability to see or hear receptive females and makes display behavior less profitable [as for tawny owls (Strix aluco): Lengagne and Slater 2002]. This was true of American woodcock (Scolopax minor), for which display activity was reduced by even light rain (Blankenship 1957). We found no relationship with rainfall on the day of the sur-

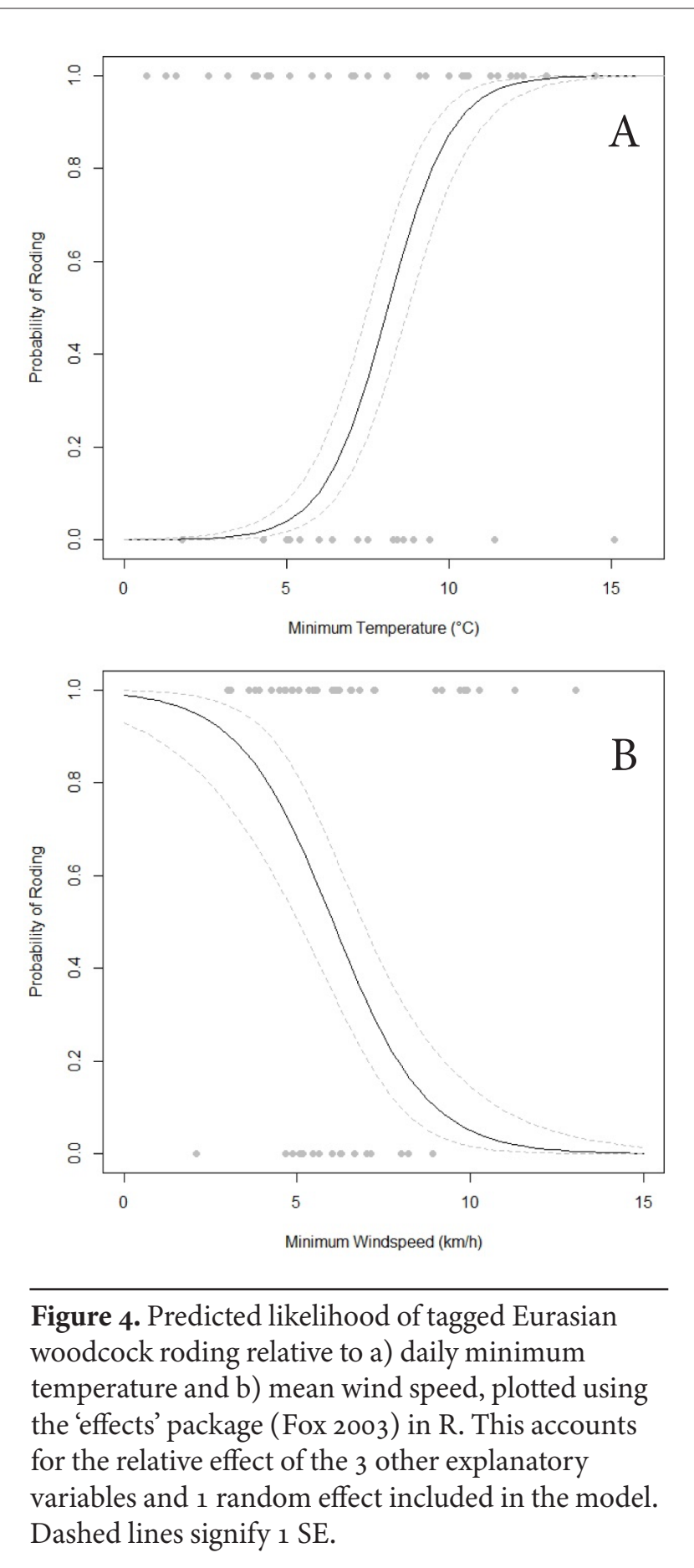


vey, but this was probably because surveys were not conducted during heavy or persistent rain, and most experienced no rainfall at all, reducing the degree of variation in our model. Our tracking data also showed no correlation with rain on the day of recording, although our daily rainfall variable does not identify whether rain fell during the logger's recording period. Whilst rain during the roding period might inhibit roding behavior, at other points during the day it might encourage roding. This was proposed for American woodcock (Blankenship 1957) and, based on personal observation, appears to be the case for Eurasian woodcock, perhaps because rainfall during the day provides the opportunity for diurnal feeding.

\section{TEMPERATURE}

We found that display behavior in tagged individuals was positively related to minimum daily temperature. This could be the product of an underlying relationship with the time of year, if both temperature and roding intensity vary in a linear fashion over the course of the breeding season, but our analyses are focused only on the peak of the roding season when roding activity tends not to show a consistent linear trend. This is reflected in our 'null' model, which found no direct correlation between the number of Eurasian woodcock registrations and the day of the year.

Woodcock may be less likely to rode on cooler evenings or following cooler days because the cost of maintaining a constant body temperature is greater and the demand to feed, rather than display, is increased. Woodcock are able to survive in much harsher conditions during the winter than are typically experienced in spring, but during the breeding season males carry minimal fat reserves (Owen and Krohn 1973) and bear greater energetic costs associated with the maintenance of reproductive physiology (Vézina and Salvante 2010) and the roding flights themselves. Alternatively, temperature might be a natural stimulus to breeding behavior as documented in other bird species (Garson and Hunter 1973). Whatever the reason, the same effect of temperature on display behavior is recorded for several other species (Slagsvold 1977, O'Connor and Hicks 1980, Gottlander 1987, Santos et al. 2009), including American woodcock (Blankenship 1957, Goudy 1960).

Whilst this relationship with temperature was not immediately apparent in the roding survey data, it became clear when minimum temperature values were logged. This probably suggests that the relationship with temperature is non-linear and that high air temperatures can also have an inhibitive effect on roding owing to lower rainfall, high rates of evaporation, and dry soils.

\section{WIND}

During roding Eurasian woodcock surveys in which the observer rated the wind as a light or moderate breeze, fewer Eurasian woodcock were encountered than during evenings that were still. Increased environmental noise could impede detection by surveyors (Alldredge et al. 2007), but our tracking data showed that tagged Eurasian woodcock were less likely to rode on windier nights, supporting a change in Eurasian woodcock behavior rather than just detectability. Males may be discouraged from roding on windier nights because their roding call is less likely to be heard by potential mates. Increased wind speeds were shown to influence the results of other bird surveys (O'Connor and Hicks 1980, Santos et al. 2009) including the Singing Grounds Survey (SGS) used to detect American Eurasian woodcock (Bergh and Andersen, this volume, Estimating density and effective area surveyed for American woodcock), and this has also been attributed to changes in Eurasian woodcock activity rather than just detection by surveyors (Blankenship 1957, Goudy 1960).

\section{CLOUD AND MOON PHASE}

We found no significant relationship between roding activity and moon phase. There are a few examples of moon phase influencing bird behavior, but these mostly relate to behavior that is truly nocturnal rather than crepuscular (Mills 1986, Dodd 1998, Mougeot and Bretagnolle 2000). Increased ambient light levels could reduce roding activity if associated with an increased predation risk (Mougeot and Bretagnolle 2000, Prugh and Golden 2014), or lengthen or delay the roding period if they improve visual signaling between males and females. This would assume dusk light levels correspond to moon phase, which seem far more dependent upon cloud cover.

Although not confirmed by our analysis, there may be a correlation between cloud cover and roding activity, particularly because the $P$-values associated with cloud cover were only marginally greater than the 0.05 threshold. Light intensity was the main stimulus for the onset of display behavior in American Eurasian woodcock and starting times were earlier in relation to sunset on cloudy evenings (Duke 1966). It seems likely the same is true for Eurasian woodcock (Heward et al. In press), which would alter survey results if it meant a proportion of the roding activity fell outside of the 75-minute survey period.

\section{Management Implications}

It appears that the display behavior of Eurasian woodcock is affected by the weather and that this can, in turn, influence the results of roding surveys. Factors such as heavy rain and strong wind were already known to discourage roding (Hoodless et al. 2006) and as a result, the British breeding Eurasian woodcock survey methodology stipulates that counts should not be conducted in these conditions (British Trust for Ornithology 2013). The more comprehensive study presented here suggests that more subtle variation in survey weather can have a detectible 
effect on count data. Further tightening the conditions in which surveys should be conducted is a possible solution, but could result in criteria that are impractically restrictive and difficult to forecast, and could discourage survey participation. Each survey site, in each year, is usually visited on 3 separate occasions, and estimates of local density are derived from the maximum count rather than the mean. This approach should provide some buffer to the effects of sub-optimal weather providing at $\geq_{1}$ count is conducted during suitable conditions. Our findings reiterate the need for all 3 visits to be completed and the exclusion of sites that do not receive them all [which has not always been the case previously (Heward et al. 2015)].

The effects of more protracted weather events, such as extended dry spells, are harder to predict. If these events affect male fitness, they are likely to affect roding behavior and, as suggested here, surveys based upon counts of displaying individuals. This is countered to some degree by the fact that repeated visits are made within the year and that each visit is separated by $\geq 1$ week. It may be sensible to separate visits with a longer interval to ensure that counts are spread over a larger portion of the breeding season and reduce the influence of seasonal variation in weather.

When unfavorable weather conditions become particularly protracted or severe, they may affect the results of roding surveys by reducing recruitment and perhaps increasing adult mortality rather than merely reducing the likelihood of Eurasian woodcock displaying. Weather has been shown to influence breeding success (Selås 2006, Guzmán and Arroyo 2015), and should therefore have an effect on roding surveys in the following year. How to separate the real demographic impacts of unfavorable weather from the behavioral responses of Eurasian woodcock based on their fitness is not currently clear. It would be possible to shed more light on these types of weather events by reanalyzing annual data to include weather variables based on the entire breeding season, not just those immediately prior to the survey. Such analyses could also incorporate measures of the weather conditions experienced in the previous breeding season and intervening winter.

There have only been 2 large-scale national surveys of breeding Eurasian woodcock in the UK to date (2003 and 2013) and these could be biased by the prevailing weather in the years they were conducted. All evidence points towards a decline in the British breeding Eurasian woodcock population that is real and long-term (Hewson and Noble 2009, Balmer et al. 2013, Heward et al. 2015), but its true scale will become clearer with each repeat of the national survey scheme as the longer time-series reduces the influence of weather in any single year. In the meantime, the complementary data provided by conducting repeat surveys at a subsample of the national survey's sites, such as those analyzed here, give some impression of annual variability in roding counts in response to weather. Repeat count data could also be used to test how successional habitat change at count points affects detection rates (Nelson and Andersen 2013). Continuing to account for weather in survey methodology, and improving the way in which this is done, will help strengthen the results of future surveys and management policies based upon them.

\section{Acknowledgments}

We are grateful to all the volunteers who conducted repeat roding surveys. We thank N. Aebischer and R. Fuller for their help and advice with survey design and interpretation, and Iain Downie for implementing the online data capture. We are grateful to the Forestry Commission, the Royal Society for the Protection of Birds, and other landowners that provided access to their land. We are grateful to the Centre for Ecology and Hydrology, the Met Office, and the Centre for Environmental Data Analysis for making the supporting datasets available. We thank the members of Birklands Ringing Group for help in the field, particularly A. Ward.

\section{Literature Cited}

Alldredge, M.W., T.R. Simons, and K.H. Pollock. 2007. Factors affecting aural detection of songbirds. Ecological Applications 17:948-955.

Balmer, D., S. Gillings, B. Caffrey, and R. Swann. 2013. Bird Atlas 2007-11: the breeding and wintering birds of Britain and Ireland. British Trust for Ornithology, Thetford, UK.

Bergh, S.M., and D.E. Andersen. 2019. Estimating density and effective area surveyed for American woodcock. Proceedings of the Eleventh American Woodcock Symposium. Pages 193-199 in D.G. Krementz, D.E. Andersen, and T. R. Cooper, Editors. Proceedings of the Eleventh American Woodcock Symposium. University of Minnesota Libraries Publishing, Minneapolis, Minnesota, USA.

Blankenship, L.H. 1957. Investigations of the American woodcock in Michigan. Final Report Number 2123. Lansing, Michigan, USA.

British Trust for Ornithology. 2013. Eurasian woodcock survey resources. <https://www.bto.org/volunteer-surveys/Eurasian woodcock-survey/resources $>$. Accessed 20 Jul 2017.

Dodd, S.L. 1998. Environmental correlates of diurnal and nocturnal foraging patterns of nonbreeding shorebirds. The Wilson Bulletin 110:182-189.

Duke, G.E. 1966. Reliability of censuses of singing male woodcocks. The Journal of Wildlife Management 30:697-707.

Estoppey, F. 2001. A declining woodcock Scolopax rusticola population in the Jorat Forest (Vaud, Western Switzerland). Nos Oiseaux 48:83-92.

Ferrand, Y., and F. Gossmann. 2009. Ageing and sexing series 5: Ageing and sexing the Eurasian woodcock Scolopax rusticola. Wader Study Group Bull. 113:75-79.

Ferrand, Y., F. Gossmann, C. Bastat, and M. Guénézan. 20o8. Monitoring of the wintering and breeding woodcock populations in France. Revista Catalana d'Ornitologia 24:44-52.

Fokin, S., and Y. Blokhin. 2013. Monitoring of the woodcock population in European Russia (1996-2010). Proceedings of the Seventh European Eurasian woodcock and Snipe Workshop 29-35.

Fox, J. 2003. Effect displays in R for generalised linear models. Journal of Statistical Software2 8:1-27. 
Game \& Wildlife Conservation Trust. 2017. Shooting of woodcock. $<$ https://www.gwct.org.uk/policy/position-statements/shooting-Eurasian woodcock/>. Accessed 26 Apr 2018.

Garson, P.J., and M.L. Hunter. 1973. Effects of temperature and time of year on the singing behaviour of wrens Troglodytes troglodytes and great tits Parus major. Ibis 121:481-486.

Gerard, B.M. 1967. Factors affecting earthworms in pastures. Journal of Animal Ecology 36:235-252.

Giunchi, D., and E. Pollonara. 2007. On sexing stone curlew Burhinus oedicnemus by cloacal examination. Wader Study Group Bulletin 113:71-72.

Gottlander, K. 1987. Variation in the song rate of the male pied flycatcher Ficedula hypoleuca: causes and consequences. Animal Behaviour 35:1037-1043.

Goudy, W.H. 1960. Factors affecting spring population indexes in southern Michigan. Thesis. Michigan State University, East Lansing, Michigan, USA.

Guzmán, J.L., and B. Arroyo. 2015. Predicting winter abundance of Eurasian woodcock Scolopax rusticola using weather data: implications for hunting management. European Journal of Wildlife Research 61:467-474.

Heward, C.J., A.N. Hoodless, G.J. Conway, N.J. Aebischer, S. Gillings, and R.J. Fuller. 2015. Current status and recent trend of the Eurasian woodcock Scolopax rusticola as a breeding bird in Britain. Bird Study 62:535-551.

Heward, C.J., A. Lowe, G.J. Conway, and A.N. Hoodless. (in Press). Timing and duration of the Eurasian woodcock's roding display: implications for survey design. Conference Proceedings of the Eighth woodcock and Snipe Workshop.

Heward, C.J., A. Lowe, and A.N. Hoodless. 2017. A method for mist-netting breeding Eurasian woodcock : use of visual and audio lures increases capture rate. Ringing and Migration 32:50-53.

Hewson, C.M., A. Amar, J.A. Lindsell, R.M. Thewlis, S. Butler, K. Smith, and R.J. Fuller. 2007. Recent changes in bird populations in British broadleaved woodland. Ibis 149:14-28.

Hewson, C.M., and D.G. Noble. 2009. Population trends of breeding birds in British woodlands over a 32-year period: relationships with food, habitat use and migratory behaviour. Ibis 151:464-486.

Hirons, G.J.M. 1980. The significance of roding by woodcock Scolopax rusticola: an alternative explanation based on observations of marked birds. Ibis 122:350-354.

Hoodless, A., D. Lang, N. Aebischer, R. Fuller, and J. Ewald. 2009. Densities and population estimates of breeding Eurasian woodcock Scolopax rusticola in Britain in 2003. Bird Study 56:15-25.

Hoodless, A.N., and G.J.M. Hirons. 2007. Habitat selection and foraging behaviour of breeding Eurasian woodcock Scolopax rusticola: a comparison between contrasting landscapes. Ibis 149:234-249.

Hoodless, A.N., J.G. Inglis, J.P. Doucet, and N.J. Aebischer. 2008. Vocal individuality in the roding calls of woodcock Scolopax rusticola and their use to validate a survey method. Ibis 150:80-89.

Hoodless, A.N., D. Lang, R.J. Fuller, N.J. Aebischer, and J.A. Ewald. 2006. Development of a survey method for breeding woodcock and its application to assessing the status of the British population. Sixth European woodcock and Snipe Workshop - Proceedings of an International Symposium of the Wetlands International woodcock and Snipe Specialist Group 25-27.

Hoodless, A.N., A. Powell, Y. Ferrand, J. Fox, G. Andrew, and O. Williams. 2013. Application of new technologies to the study of Eurasian woodcock migration. Proceedings of the Seventh European woodcock and Snipe Workshop.

Lengagne, T., and P.J.B. Slater. 2002. The effects of rain on acoustic communication: tawny owls have good reason for calling less in wet weather. Proceedings of the Royal Society B: Biological Sciences 269:2121-2125.

Lutz, M. 2005. European management plan for woodcock Scolopax rusticola 2006-2009 (Draft). Le Sambuc, France.

Machado, A.L., Y. Ferrand, F. Gossmann, A.M. Silveira, and D. Gonçalves. 2008. Application of a roding survey method to the sedentary Eurasian woodcock Scolopax rusticola population in Pico Island, Azores. European Journal of Wildlife Research 54:205-214.

Met Office. 2017a. UKCPo9: Met Office gridded land surface climate observations - daily temperature and precipitation at $5 \mathrm{~km}$ resolution. Centre for Environmental Data Analysis accessed 20 Aug 2017.

Met Office. 2017b. Met Office Observation Data. <https://data.gov. uk/metoffice-data-archive >. Accessed 18 Jul 2017.

Mills, A.M. 1986. The influence of moonlight on the behavior of goatsuckers (Caprimulgidae). The Auk 103:370-378.

Morton, D., C. Rowland, C. Wood, L. Meek, C. Marston, G. Smith, R. Wadsworth, and I. Simpson. 2011. Final Report for LCM2007 - the new UK land cover map. Countryside Survey Technical Report No 11/07.

Mougeot, F., and V. Bretagnolle. 20oo. Predation risk and moonlight avoidance in nocturnal seabirds. Journal of Avian Biology 31:376-386.

Nelson, M.R., and D.E. Andersen. 2013. Do singing-ground surveys reflect American woodcock abundance in the western Great Lakes region? Wildlife Society Bulletin 37:585-595.

O'Connor, R.J., and R.K. Hicks. 1980. The influence of weather conditions on the detection of birds during common birds census fieldwork. Bird Study 27:137-151.

Owen, R.B., and W.B. Krohn. 1973. Molt pattern and weight changes in American woodcock. Wilson Bulletin 85:31-41.

Prugh, L.R., and C.D. Golden. 2014. Does moonlight increase predation risk? Meta-analysis reveals divergent responses of nocturnal mammals to lunar cycles. Journal of Animal Ecology 83:504-514.

R Development Core Team. 2016. R: a language and environment for statistical computing. R Foundation for Statistical Computer, Vienna, Austria.

Santos, M., P. Travassos, M. Repas, and J.A. Cabral. 2009. Modelling the performance of bird surveys in non-standard weather conditions: general applications with special reference to mountain ecosystems. Ecological Indicators 9:41-51.

Seamans, M.E., and R.D. Rau. 2017. American woodcock population status, 2017. U.S. Fish and Wildlife Service 17.

Selås, V. 2006. Patterns in grouse and woodcock Scolopax rusticola hunting yields from central Norway 1901-24 do not support the alternative prey hypothesis for grouse cycles. Ibis 148:678-686.

Slagsvold, T. 1977. Bird song activity in relation to breeding cycle, spring weather and environmental phenology. Ornis Scandinavia 8:197-222.

Somacon.com. 2011. Moon phases for PHP script (CSV format). $<$ http://www.somacon.com/p570.php>. Accessed 31 Aug 2017.

Tanguy, M., H. Dixon, I. Prosdocimi, D.G. Morris, and V.D.J. Keller. 2016. Gridded estimates of daily and monthly areal rainfall for the United Kingdom (1890-2015) [CEH-GEAR]. NERC Environmental Information Data Centre.

Tomkovich, P.S., and M.Y. Soloviev. 1996. Distribution, migrations and biometrics of knots Calidris canutus canutus on Taimyr, Siberia. Ardea 84:85-98.

Venables, W.N., and B.D. Ripley. 2002. Modern applied statistics with S. Springer, New York, New York, USA.

Vézina, F., and K.G. Salvante. 2010. Behavioral and physiological flexibility are used by birds to manage energy and support investment in the early stages of reproduction. Current Zoology $56: 767-792$. 